\title{
Suppression of Thyroid Function by Seaweed "Kombu" (Laminaria japonica) Supplement Seen in a Patient with Alopecia Areata: A Case Report
}

\author{
Shigeki Inui ${ }^{*}$, , Naoyuki Tsujimoto ${ }^{2}$, Naoyuki Toda ${ }^{3}$ and Satoshi Itami ${ }^{1}$ \\ ${ }^{I}$ Department of Regenerative Dermatology, Graduate School of Medicine, Osaka University, Osaka, Japan \\ ${ }^{2}$ Department of Internal Medicine, Kuma Hospital, Hyogo, Japan \\ ${ }^{3}$ Shin-Osaka Clinic, Osaka, Japan
}

\begin{abstract}
A 36-year old woman with severe alopecia areata was treated by intravenous corticosteroid pulse therapy, resulting in complete remission a year later. At her visit to us for follow-up, we found her thyroid swelling while she did not feel any symptom indicative of thyroid abnormality. Careful history taking revealed that she had kept taking supplement of seaweed "Kombu" (Laminaria japonica) (1g rhizoid/day) by herself for a year. Results of blood tests were: free T3, $2.7 \mathrm{pg} / \mathrm{ml}$ (normal: $2.3-4.3 \mathrm{pg} / \mathrm{ml}$ ); free T4, $0.7 \mathrm{ng} / \mathrm{ml}$ (normal: $0.9-1.7 \mathrm{ng} / \mathrm{ml}$ ) and TSH, $27.5 \mu \mathrm{U} / \mathrm{ml}$ (normal: 0.5 $5.0 \mu \mathrm{U} / \mathrm{ml})$ in the serum. Thyroid echo imaging revealed weight of thyroid as $28.68 \mathrm{~g}$, which is larger than normal $(8-20$ g). Collectively, we diagnosed her as having thyroid suppression by iodine of the seaweed supplement and therefore advised her to prohibit its intake. Two months later, her blood tests showed normalization of thyroid hormone synthesis.
\end{abstract}

Keywords: Hypothyroidism, Laminaria japonica, iodine, side effect.

\section{CASE PRESENTATION}

A 36-year old woman with severe alopecia areata (AA) (S4; 75-99\% hair loss on the scalp) was treated by intravenous corticosteroid pulse therapy [1], resulting in complete remission a year later. Her father had suffered from Hashimoto disease (autoimmune hypothyroidism). At her visit to us for follow-up, we found her thyroid swelling while she did not feel any symptom indicative of thyroid abnormality. Careful history taking revealed that she had kept taking supplement of seaweed "Kombu" (Laminaria japonica) (1g rhizoid/day) by herself for a year because she believed that it could prevent relapse of AA owing to Japanese classical superstition that Laminaria might stimulate or maintain hair growth. Then, we recommended more scrutiny of thyroid and results of blood tests were: free T3, $2.7 \mathrm{pg} / \mathrm{ml}$ (normal: $2.3-4.3 \mathrm{pg} / \mathrm{ml}$ ); free T4, $0.7 \mathrm{ng} / \mathrm{ml}$ (normal: $0.9-1.7 \mathrm{ng} / \mathrm{ml}$ ) and $\mathrm{TSH}, 27.5 \mu \mathrm{U} / \mathrm{ml}$ (normal: 0.5 $5.0 \mu \mathrm{U} / \mathrm{ml}$ ) in the serum, indicating suppression of thyroid function. Thyroid echo imaging revealed the right and left thyroid lobule as 6.6 and $5.8 \mathrm{~cm}$ in height, 1.9 and $1.7 \mathrm{~cm}$ in width and 2.0 to $1.6 \mathrm{~cm}$ in depth, respectively (Fig. 1), and further the weight of thyroid as $28.68 \mathrm{~g}$, which is larger than normal (8-20 g), demonstrating thyroid swelling observed by physical examination. On the other hand, serum antithyroglobulin and anti-thyroid peroxidase antibodies were negative, ruling out autoimmunity against thyroid. Although some drugs may affect thyroid function [2], there is no concurrent drug treatment. Additionally, other factors

*Address correspondence to this author at the Department of Regenerative Dermatology, Graduate School of Medicine, Osaka University, 2-2 G2, Yamada-oka, Suita-shi, Osaka 5650871, Japan; Tel: +81-6-6879-3960; Fax: +81-6-6879-3962; E-mail: inui@r-derma.med.osaka-u.ac.jp influencing iodine half-life could not be detected. Further, fine needle aspiration biopsy revealed no significant lymphocyte infiltration into thyroid, denying thyroiditis. Collectively, we diagnosed her as having thyroid suppression by iodine of the seaweed supplement (Wolff-Chaikoff effect) [3] with thyroid hypertrophy by increased TSH and therefore advised her to prohibit its intake. Two months later, her blood tests were: free T3, $2.54 \mathrm{pg} / \mathrm{ml}$; free T4, $0.9 \mathrm{ng} / \mathrm{ml}$ and $\mathrm{TSH}, 3.85 \mu \mathrm{U} / \mathrm{ml}$, suggesting normalization of thyroid hormone synthesis. Thyroid echo showed that her thyroid size returned to normal level. During this course no relapse of hair loss occurred.

\section{COMMENTS}

From ancient days, beautiful long hairs of females have been compared to seaweeds in Japan as seen in the tale of Genji, written in the eleventh century, where Genji composed the Japanese poem for Murasaki-no-ue, "Rich seaweed tresses of the unplumbed ocean depths, a thousand fathoms long, you are mine and mine alone to watch daily as you grow", to praise her beautiful hairs [4]. From this tradition even today Japanese are apt to believe seaweeds to be helpful for hair growth or quality although there are no published scientific evidences of correlation between alopecia and iodine or seaweed intakes. On the other hand, excess iodine, an essential element of thyroid hormones, causes not only hyperthyroidism but also hypothyroidism, known as Wolff-Chaikoff effect [3], whereas iodine deficiency induces hypothyroidism. Japan is an iodine-rich area probably because of seaweed intake, evidenced by previous reports showing that urinary iodine excretion by normal Japanese is 0.06-9.3 mg/day [5-9], being higher than 0.03-0.7 mg/day by foreigners [5]. Moreover, recent 


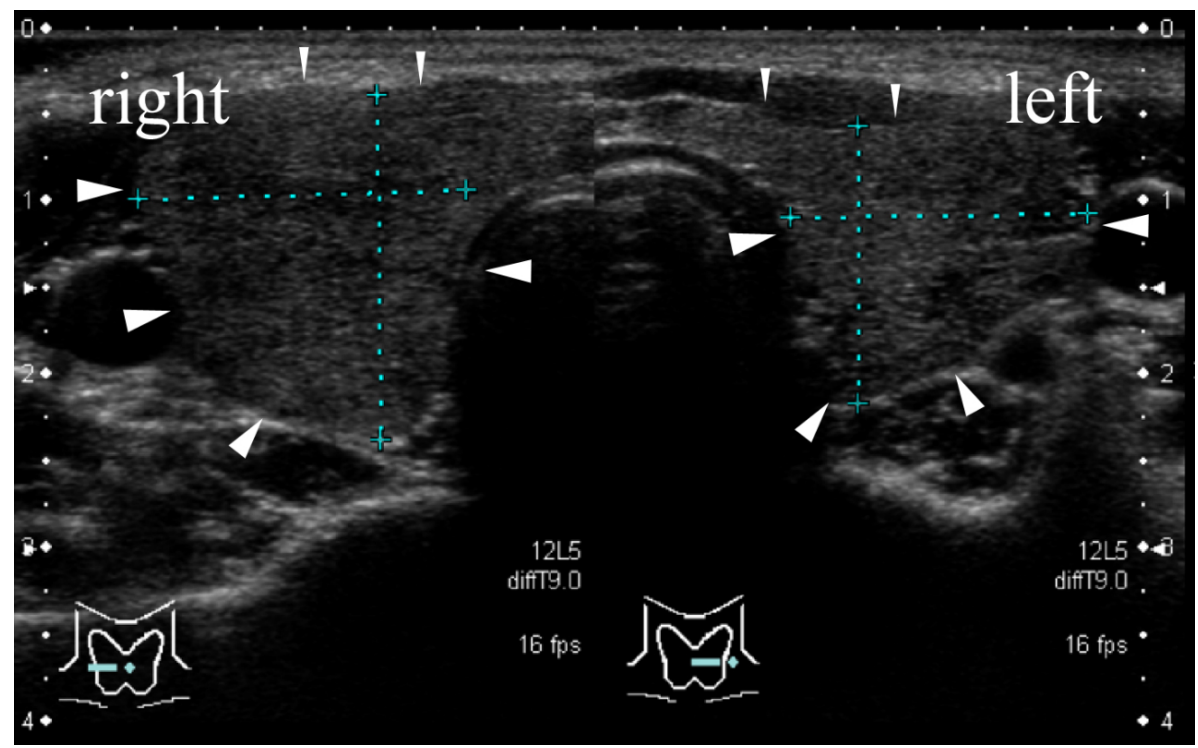

Fig. (1). Thyroid echo imaging revealed the right and left thyroid lobule as 6.6 and $5.8 \mathrm{~cm}$ in height, 1.9 and $1.7 \mathrm{~cm}$ in width and 2.0 to 1.6 $\mathrm{cm}$ in depth, respectively.

experimental study showed that ingestion of $15 \mathrm{~g}$ Laminaria (35mg iodine)/day for 7-10 days induces abnormal increase of serum TSH concentration in 4 of 6 normal Japanese and serum free T3 and T4 were slightly lowered within normal limits [10]. From the epidemiologic point of view, endemic goiter was previously observed in north coast area of Hokkaido, Japan, where seaweed is routinely eaten with daily meals [11]. Among 218 people in the area, 38 (13.9\%) had goiter while all of them were euthyroid. In additon, recently it was reported that, among consecutive 33 patients with hypothyroidism, $21(63.6 \%)$ patients show a decrease in serum TSH and $11(33.3 \%)$ become euthyroid after iodine restriction [12]. Based on these findings Japanese people should be recommended to avoid ingestion of excessive amounts of seaweeds. Because our patient had family history of Hashimoto disease, we checked autoimmune thyroiditis but could not obtain such evidence. However, we should carefully follow up for possible development of autoimmune hypothyroidism in the future. Moreover, our case here indicated an important lesson to carefully ask patients with hair loss about their intake of supplements, which possibly contain seaweed or iodine.

\section{REFERENCES}

[1] Nakajima T, Inui S, Itami S. Pulse corticosteroid therapy for alopecia areata: study of 139 patients. Dermatology 2007; 215: $320-4$.
[2] Dong BJ. How medications affect thyroid function? West J Med 2000; 172: 102-6.

[3] Markou K, Georgopoulos N, Kyriazopoulou V, Vagenakis AG. Iodine-induced hypothyroidism. Thyroid 2001; 11: 501-10.

[4] Murasaki S. Aoi: Heart-to-heart. In: Tyler R, Ed. The tale of Genji, abridged. London, Penguin Books 2006; pp. 162-85.

[5] Yabu Y, Miyai K, Hayashizaki S, et al. Measurement of iodide in urine using the iodide-selective ion electrode. Endocrinol Jpn 1986; 33: 905-11.

[6] Yabu Y, Miyai K, Endo Y, et al. Urinary iodide excretion measured with an iodide-selective ion electrode: studies on normal subjects of varying ages and patients with thyroid diseases. Endocrinol Jpn 1988; 35: 391-8.

[7] Konno N, Yuri K, Miura K, Kumagai M, Murakami S. Clinical evaluation of the iodide/creatinine ratio of casual urine samples as an index of daily iodide excretion in a population study. Endocr $\mathrm{J}$ 1993; 40: 163-9.

[8] Namba H, Yamashita S, Kimura $\mathrm{H}$, et al. Evidence of thyroid volume increase in normal subjects receiving excess iodide. J Clin Endocrinol Metab 1993; 76: 605-8.

[9] Nagata K, Takasu N, Akamine H, et al. Urinary iodine and thyroid antibodies in Okinawa, Yamagata, Hyogo, and Nagano, Japan: the differences in iodine intake do not affect thyroid antibody positivity. Endocr J 1998; 45: 797-803.

[10] Miyai K, Tokushige T, Kondo M. Suppression of thyroid function during ingestion of seaweed "Kombu" (Laminaria japonoca) in normal Japanese adults. Endocr J 2008; 55: 1103-8.

[11] Suzuki H, Higuchi T, Sawa K, Ohtaki S, Horiuchi Y. Endemic coast goitre in Hokkaido, Japan. Acta Endocrinol (Copenh) 1965; 50: $161-76$.

[12] Kasagi K, Iwata M, Misaki T, Konishi J. Effect of iodine restriction on thyroid function in patients with primary hypothyroidism. Thyroid 2003; 13: 561-7. 